\title{
The Influence of Cash Flow Patterns on Random Organizational Development in Nigerian Listed Companies
}

\author{
Chizoba Ekwueme ${ }^{1}$, Rosemary Obiageri Obasi ${ }^{2}$, Sadiq Rabiu Abdullahi ${ }^{3}$, Umar Aliyu Mustapha ${ }^{4} \&$ Norfadzilah \\ Rashid $^{4}$ \\ ${ }^{1}$ Department of Accountancy, Nnamdi Azikiwe University, Awka, Anambra State, Nigeria \\ ${ }^{2}$ Department of Accounting, Benson Idahosa University, Benin City, Edo State, Nigeria \\ ${ }^{3}$ Department of Accounting, Faculty of Management Sciences, Bayero University, Kano, Nigeria \\ ${ }^{4}$ Faculty of Business \& Management Science, Universiti Sultan Zainal Abidin, Terengganu, Malaysia \\ Correspondence: Norfadzilah Rashid, Faculty of Business \& Management Science, Universiti Sultan Zainal Abidin, \\ Terengganu, Malaysia.
}

Received: February 17, 2020

Accepted: March 23, 2020

Online Published: June 16, 2020

doi:10.5430/rwe.v11n3p171

URL: https://doi.org/10.5430/rwe.v11n3p171

\begin{abstract}
The objective of this study is to examine whether companies' life cycle stages follow a random or sequential developmental pattern using their cash flow patterns. That is to ascertain the optimum life cycle stage of Nigerian companies. Data were obtained from the sampled firms annual reports and accounts, which comprises 79 listed companies on the Nigerian Stock Exchange (NSE) from 2009 to 2013 financial years. The cash flow patterns of the firms were thematically analysed as a proxy of developmental patterns, and transition rates between developmental stages were determined. The study reveals that Introduction firms at T0 transited quickly to the Mature stage (70\% in T1 through T3), whereas Growth firms developed most rapidly into Shakeout firms (38\% at T1). The Mature stage was most stable; $57-65 \%$ of firms in this stage at T0 remained so. By contrast, $60 \%$ of Decline firms remained in this stage at $\mathrm{T} 1$ before transiting to the Mature and Growth stages at $\mathrm{T} 3$ and then ultimately fading away at $\mathrm{T} 4$, leaving only the Introduction (20\%) and Decline (20\%) stages. Thus, the development of firms from one life cycle stage to another is random and not sequential. The study, therefore, recommends that Nigerian companies experience their optimum life cycle stage at the matured stage and firms should employ the use of cash flow patterns to identify their business life cycle stage as this will enable companies to apply strategies to sustain themselves at a target stage of the life cycle.
\end{abstract}

Keywords: business life cycle, cash flow patterns, firm development pattern, mature firm, Nigeria

\section{Introduction}

The importance of identifying the life cycle stage of any phenomenon cannot be over-emphasized. Parker (2018) stated that "There is a life cycle for everything, and likewise a country also has its life cycle. It is being proved by many philosophers and sociologists how's make available literature on that. This quote summaries how political researchers and sociologist perceive the importance of societal life cycle talk less that of companies; the ability to achieve this feat by the accountant is one of the challenges which this study helped to throw more light on the current status of the Nigerian company's life cycle. Obasi and Ekwueme (2016) showed that the use of cash flow patterns is the best option to classified companies into its life cycle in Nigeria.

However, not only the importance of the Organisational Life Cycle (OLC) concept, two main issues occur when it comes to an understanding and using the term. Firstly, there seems to be no agreement on the operational definition that should be used to distinguish the stages of the life cycle. This result is in a wide disparity of the life cycle model in an organisation or the number of life cycle stages of an organisation. The studies of Miller \& Friesen (1983), \& (1984), and Dickinson, (2011) highlighted five-stage, while the study of Pashley \& Philippatos (1990) come up with four-stages and three-stage models were developed by Anthony \& Ramesh (1992). Consequently, there is an issue of non-existence for the established methodology to identify each life cycle stage. There is also an issue with methods projected in the existing life cycle studies which offer an inconsistent approach to the organisational life cycle classification process. 
Thus, it is being solved using the cash flow patterns as proposed by Dickson (2011) in the United States and supported by Obasi and Ekwueme (2016) using Nigerian companies. Obasi and Ekwueme (2016) showed that the cashflow patterns best classify Nigerian companies into their life cycle stages as compared by the use of Age as a proxy for firm life cycle classification. In furtherance of Obasi and Ekwueme's study, this study ascertained whether all companies evolve through the same series of stages. As a result, the following questions were posed: do the life cycle patterns of companies proceed through stages sequentially or randomly? Is it possible to identify the optimum life cycle stage for Nigerian companies?

Nevertheless, most of the life cycle literature are developed in conceptual design relatively than empirical structured. This recommends that supplementary empirical evidence is needed in this area of research. Also, Nigerian firms were studied in this case because studies on life cycle stages only covered developed countries. There are no life cycle studies on Africa companies. Hence, Nigeria, as one of the largest African countries, was studied, and the results can explain the circumstances of other African countries. However, the evolution of companies is a global phenomenon; such that, the relevance of the result cuts across Local and International boundaries.

The empirical evidence of this study will be of significance to stakeholders seeking to estimate the stage of an entity for purposes of investment or monitoring. The results also contribute to the life cycle literature by shedding light on arguments against the random hypothesis of the firm life cycle. In all, understanding the organisational life cycle is based on the capability to identify where the company is in its life cycle and recognise critical organisational developments as well as disadvantages that should be avoided by the company also, for researchers to identify and make recommendations to address the category of firms studied instead of spurious recommendations as we observe presently. The content of this paper is arranged according to the following. The first section of the introduction, the next section discusses the relevant literature and the summary following the methods and data obtained. After analysing and discussing the results, conclusions and recommendations are presented.

\section{Literature Review and Hypotheses Development}

\section{Firm life cycle as a concept}

The expected sequence of advancements experienced by a firm is known as the firm life cycle (Bess, 1984). There is no consensus on the definition of the life cycle stages (Jaafar \& Halim, 2015). However, researchers have shown that the concept of a life cycle also applies to organisations (Anthony \& Ramesh, 1992; Dickinson, 2011; Obasi \& Ekwueme, 2016). Mason Haire's 1959 work “Modern Organizational growth" is generally recognised as among the first to use a biological model for organisational growth. Hanks, Watson, Jansen, and Chandler (1993) defines the life cycle stage as a unique composition of the variables related to the context and structure of the organisation and confirms that the lack of a clear definition of life cycle stages leads to difficulties in applying the concept to specific situations.

Based on the descriptions used in each stage of the life cycle, it makes two notable observations. First, building a life cycle stage appears to be a multidimensional phenomenon and secondly, while there is an excellent contrast between life cycle models, all of which include some dimensions related to the organisational context and structure. Examples of the organisational context include the size of the company, the rate of sales growth, key strategies, focus tasks and challenges facing the company, while examples of the organisational structure include the basic form, formalisation, centralisation, leadership and management style. These dimensions are interlinked and interconnected, and differences in the pattern and size of these dimensions separate the life cycle stage from another (Jaafar \& Halim, 2015).

\section{Extant studies on Life cycle developmental stages}

The use of the corporate age as a proxy for the life cycle stage implies that the company moves sequentially throughout the life cycle stages. However, significant product innovations, expansion into new markets or structural changes can cause companies to recycle throughout the life cycle in a non-sequential manner. Moreover, companies of the same age may learn at different rates due to defects in the feedback mechanisms (such as accounting quality), and therefore the life of the company may differ from the life cycle stage of the company (Dickinson, 2011). The company's life cycle is a set of distinct and interrelated product life stages and thus may be difficult or impossible to determine (Anthony and Ramesh, 1992). However, researchers have shown that the firm life cycle can be determined given certain assumptions (Anthony and Ramesh, 1992; Dickinson, 2011; Obasi and Ekwueme, 2016).

Most of the subsequent accounting studies (for example, Black 1998, Martinez, 2003, Jenkins, Kane, \& Velury, 2004, Kousenidis, 2005) that examine a firm's lifecycle are based on the four primary classification method introduced by Anthony and Ramesh (1992). The four classifications are Income Ratio (DP), Sales Growth Ratio (SG), Capital Expenditure as a percentage of the Company's Total Value (CEV), and Company Age (AGE). These variables are chosen to repeat reference in literature, accounting, economics and management. Moreover, Anthony and Ramesh 
(1992) argue that since the financial classification variables used are also directly related to the Company's risk, companies sorted by these variables may have a differential response to performance measures, even without life-cycle considerations.

Consequently, a non-monetary variable (AGE) is chosen to reduce the impact of the potential correlation of risk with the life cycle stages. The argument is that companies, in the early stages of their life cycle, show higher sales growth, have a higher investment in plants and equipment, and lower dividend ratios given their opportunity in a set of positive net present value projects. Moreover, young companies are likely to have new products. Companies are categorised throughout their life cycle using single-variable classification procedures and multiple variables. In a single variable procedure, companies are categorised into each of the four life cycle descriptors and grouped into different stages of the life cycle each year.

Then, each firm is given a score: growth $=1$, ripe $=2$, and stagnation $=3$. In the multivariate arrangement procedure, the combined score is calculated by summing the individual variable scores. Based on this composite score, each year-long observation is assigned to five life-cycle groups: growth, growth/maturity, mature, mature/stagnant and stagnant. Like other previous methods, there are also many issues with the Lifecycle Classification procedure. Haire (1959) was the first researcher to postulate that organisational growth and development follow a regular sequence. His model of the organisational life cycle proposes that business firms move through a relatively predictable sequence of developmental stages over time (Gibson et al., 1994; Adizes, 1989; Quinn \& Cameron, 1983; Greiner, 1972). The OLC model is based on a biological metaphor; i.e., business firms exhibit a regular pattern of development and thus resemble living organisms. Quinn and Cameron (1983) characterised these developmental stages as sequential and following a hierarchical, largely irreversible progression involving a wide variety of organisational activities and structures.

On the other side of the divide, some researchers believe that the firm life cycle cannot be likened to the human life cycle, which has a sequential growth pattern (Tichy, 1980; Miller \& Friesen, 1984; Dickson, 2011). However, attempts to test the sequential hypothesis have failed due to a lack of agreed-upon indicators of the life cycle stage. Obasi and Ekwueme (2016) recently obtained support for Dickinson's (2011) suggestion that cash-flow patterns best explain the firm life cycle stage as compared to the proxy Age. Based on this finding, this study strives to test the random hypothesis of the firm life cycle.

Conceptual literature generally assumes a sequence of stages that is consistent, orderly, and not easily reversible and progresses from the beginning stage to growth to maturity, and finally, to revival or retreat (Quinn \& Cameron, 1983, Adizes, 1989, Greiner, 1972) Empirical studies provide some evidence of the existence of an inconclusive sequence of life cycle stages (Tichy, 1980; Miller \& Friesen, 1984; Lester, Parnell, \& Carraher, 2003, Dickson, 2011). Specifically, it was found that although the majority of companies tend to demonstrate long-term evolutionary patterns similar to those proposed in life-cycle literature, there are still some companies that fail to demonstrate the development of the shared life-cycle. It indicates that there are a large number of transitional paths available to organisations and that company development does not necessarily correspond to the predictable pathways proposed in the life cycle theory. In general, it is necessary to ensure that there are laboratories inherent in the development and application of the life cycle concept.

Studies such as Miller and Frizen (1984), Lester, Parnell, and Kahr (2003) have revealed non-deterministic life cycles for companies and confirm that most companies do not move from one stage to another of evolution to another in the traditional biological sense. For example, Miller and Frizen (1984) highlighted that companies that grow up but do not grow and diversify, are unlikely to move between stages. Although older firms tend to be more sophisticated, detailed and bureaucratic than their younger counterparts, they suggest this is mostly due to growth and strategy rather than maturity. Second, rating companies can lead to stages of a life cycle by ranking them among all companies every year, leading to poor rating and reducing the strength of tests. That is because each company is different and has a unique path to development (Fisher, 2006).

For example, while 10 percent sales growth may be somewhat high for a company in a stable industry, such as food and beverages, it may be low for a company in the pharmaceutical and biotechnology industry. However, the main advantage of this method is that it includes some interactions between different variables in determining the stages of the life cycle. While a single-variable classification that uses only one agent has the potential to cause a classification error (Black, 1998, Gaver \& Gaver, 1993), multivariate classification can provide more accurate results. This is because co-existence, for example, high sales growth and high capital expenditures, is likely to prevent the classification of companies with cash flow problems that are not growth companies. 
Other studies that applied the method introduced by Anthony and Ramesh (1992) did so with some modifications. For example, Black (1998) sample firms are also assigned to growth, mature, and lower stages. However, the life-cycle classification method is based on one-fifth of the combined grades. Recently, Park and Chen (2006), Yan, and Zhao (2010) have looked at the potential impact of the industry by rating companies relative to other companies in their industry and using only the adjusted sales growth rate in the industry, respectively. Based on existing literature, there is no consistent development pattern for an organisation's life cycle. It is as a result of two factors; first, there is no clear definition of the life cycle, and secondly, agents used to date have been criticized for rating companies. Thus, this study proposes to address the research issue. The following hypothesis is suggested:

\section{$H_{1}$ Nigerian companies do not develop sequentially}

\section{Classification proxy for life cycle stages}

A superior model for firm life cycle classification was proposed in Dickinson (2011) study that has been tested and supported in Obasi and Ekwueme (2016). The use of cash flow patterns to classify firms into their life cycle stages. The classification model, when tested in comparison with age as a proxy, showed support for most of the predictions (see Dickinson, 2011, Obasi \& Ekwueme, 2016). The cash flow patterns criteria are needed to broaden the use of the model in the analysis of financial reporting practices of firms. Therefore, using cash flow patterns as life cycle proxies, the classification procedure is as follows.

From the statement of cash flow, there are three subsections, which are, the operating activities, investing and financing sections. The sign of the end products of these sections is patterned in refined combinations as they exhibit the nature and stage of a firm. Below is a description of the patterns:

\section{LIFE CYCLE STAGE}

Introduction stage

Growth stage

Maturity stage

Shake-out stage

Decline stage

\section{CASH FLOW PATTERN}

$$
\begin{aligned}
& \mathrm{CFO}(-), \mathrm{CFI}(-) \text { and } \mathrm{CFF}(+) \\
& \mathrm{CFO}(+), \mathrm{CFI}(-) \text { and } \mathrm{CFF}(+) \\
& \mathrm{CFO}(+), \mathrm{CFI}(-) \text { and CFF (-) } \\
& \mathrm{CFO}(-/+), \mathrm{CFI}(-/+) \text { and CFF (-/+) } \\
& \mathrm{CFO}(-/+), \mathrm{CFI}(+) \text { and CFF (+/-) }
\end{aligned}
$$

Source: (Dickson, 2011)

\section{Methods and Data}

The sample comprised companies listed on the Nigerian Stock Exchange (NSE) as of 2009-2013. As of June 2014, the NSE included 13 main sectors, several subsectors, and 223 listed entities. Many of the listed entities have foreign or multinational affiliations and represent a cross-section of the economy ranging from agriculture to manufacturing and service (NSE Factbook, 2013). Each company in the sample fulfilled its obligation to deliver an annual report for the year 2016. This study focused on ten (10) sectors that are not classified as regulated sectors. Three sectors (banking and insurance, brokers and services; and memorandum quotations) were omitted because they are highly regulated or too specialised and thus might not experience natural developmental tendencies (Dickinson, 2011). The final sample thus comprised of 79 companies, as shown in Table 1 in appendix A.

Secondary data were obtained from the selected listed companies' financial reports for the years 2009-2013, focusing on firms with six to seven years of continuous reports see (Muatapha, Rashid, Bala, \& Musa, 2020). Data were available for 77 entities in 2010, and this number decreased to 46 in 2013; after that, it was so challenging to collect continuous data for the companies. To collect the data, a list of publicly listed companies on the NSE was first compiled from the NSE library using the NSE factbook. Additional information about these companies was subsequently extracted from their websites via Google search and from their published annual reports.

When necessary, the data sources were complemented by the NSE statistical bulletin. The cash flow patterns proposed by Dickinson (2011) were adopted because the findings of Obasi and Ekwueme (2016) support Dickinson's claim that Cash Flow Patterns determine firm life cycle stages better than firm Age. After grouping the firms into their various stages from as denoted by the patterns, the companies were therefore analysed thematically from the year of classification through some number of years to show the trend in their development over the years. 


\section{Data Analysis and Results}

The collected data were analysed using the descriptive statistical analysis technique. The life cycle stages of the entities at time $\mathrm{T}_{0}$ were compared with those at $\mathrm{T}_{1}, \mathrm{~T}_{2}, \mathrm{~T}_{3}$. This analysis revealed changes in the life cycle stages of the entities over several years.

Table 1 . Life cycle stages as determined by cash flow pattern

\begin{tabular}{lllllll}
\hline & 2009 & 2010 & 2011 & 2012 & 2013 & TOTAL \\
Introduction & 7 & 6 & 4 & 5 & 2 & 24 \\
Growth & 8 & 9 & 14 & 7 & 6 & 44 \\
Mature & 41 & 52 & 41 & 37 & 31 & 202 \\
Shakeout & 7 & 4 & 6 & 3 & 2 & 22 \\
Decline & 13 & 6 & 5 & 9 & 8 & 41 \\
\hline
\end{tabular}

As shown in Table 3, in 2009, 7 companies were in the Introduction stage, 8 in the Growth stage, 41 in the Mature stage, 7 in the Shakeout stage and 13 in the Decline stage. A thematic analysis of these companies was performed using the year 2009 as $\mathrm{T}_{0}$ and 2010 to 2013 as $\mathrm{T}_{1}$ to $\mathrm{T}_{4}$, respectively.

To determine if firm development follows a regular sequence, the transition rate, i.e., the rate at which the firms proceeded from one life cycle stage to another was examined. The transition rates, as reflected by the proportion of companies in each stage at each time point, are shown in Table 4.

Table 2. Development of analysis in proportion of firms transiting beyond the portfolio formation period

\begin{tabular}{|c|c|c|c|c|c|}
\hline \multirow[t]{2}{*}{ The stage at portfolio formation $\left(\mathrm{T}_{0}\right)$} & \multirow[t]{2}{*}{ Stage in the future period } & $\mathrm{T}_{1}$ & $\mathrm{~T}_{2}$ & $\mathrm{~T}_{3}$ & $\mathrm{~T}_{4}$ \\
\hline & & $\%$ & $\%$ & $\%$ & $\%$ \\
\hline \multirow[t]{5}{*}{ Introduction } & Introduction & 10 & 10 & 20 & 20 \\
\hline & Growth & 10 & - & - & - \\
\hline & Mature & 70 & 70 & 70 & 80 \\
\hline & Shakeout & - & - & - & - \\
\hline & Decline & 10 & 20 & 10 & - \\
\hline \multirow[t]{5}{*}{ Growth } & Introduction & 13 & 25 & - & - \\
\hline & Growth & 25 & 13 & 13 & 25 \\
\hline & Mature & 25 & 38 & 63 & 38 \\
\hline & Shakeout & 38 & - & 13 & 13 \\
\hline & Decline & - & 25 & 13 & - \\
\hline \multirow[t]{5}{*}{ Mature } & Introduction & 5 & 5 & 3 & 3 \\
\hline & Growth & 22 & 11 & 14 & 19 \\
\hline & Mature & 57 & 60 & 65 & 57 \\
\hline & Shakeout & 3 & 5 & - & 5 \\
\hline & Decline & 5 & 5 & 5 & 8 \\
\hline \multirow[t]{3}{*}{ Shakeout } & Introduction & 17 & - & 8 & - \\
\hline & Growth & 33 & - & - & 8 \\
\hline & Mature & 50 & 58 & 58 & 42 \\
\hline
\end{tabular}


The stage at portfolio formation $\left(\mathrm{T}_{0}\right)$ Stage in the future period

$\begin{array}{llll}\mathrm{T}_{1} & \mathrm{~T}_{2} & \mathrm{~T}_{3} & \mathrm{~T}_{4} \\ \% & \% & \% & \%\end{array}$

\begin{tabular}{|c|c|c|c|c|c|}
\hline & Shakeout & - & 8 & 17 & 17 \\
\hline & Decline & - & 8 & 17 & 8 \\
\hline \multirow{5}{*}{ Decline } & Introduction & - & - & - & 20 \\
\hline & Growth & 20 & 20 & 20 & - \\
\hline & Mature & 20 & - & 80 & - \\
\hline & Shakeout & - & 20 & - & - \\
\hline & Decline & 60 & 40 & - & 20 \\
\hline
\end{tabular}

As indicated by the data in the table, Introduction firms transited quickly to the Mature stage (e.g., $70 \%$ in $\mathrm{T}_{1}$ to $\left.\mathrm{T}_{3}\right)$, reaching $80 \%$ in $\mathrm{T}_{4}$. This sketch is demonstrated graphically in Figure 1.

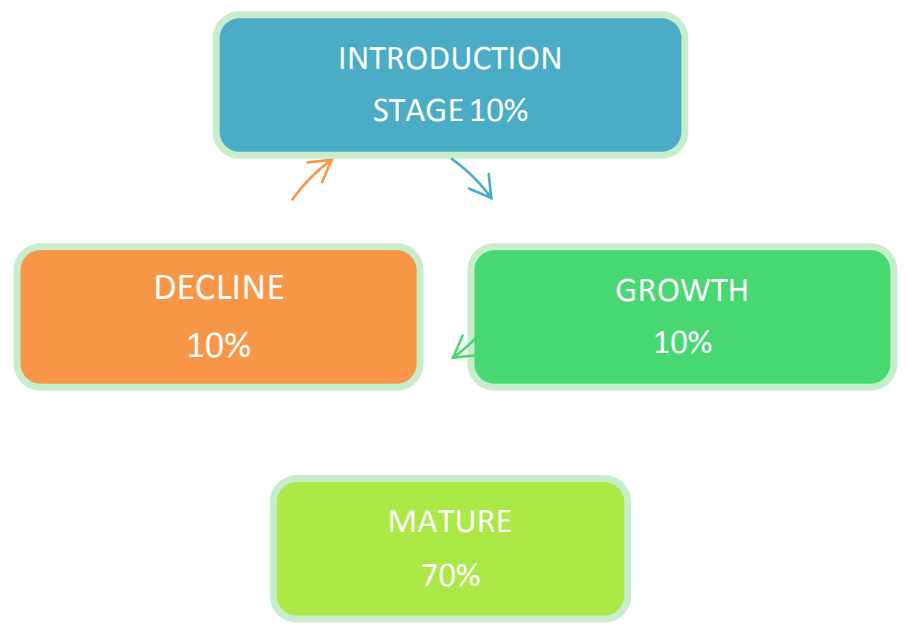

Figure 1 . The life cycle stages at $\mathrm{T}_{1}$ of entities in the introduction stage at $\mathrm{T}_{0}$

As shown in Figure 1, among the entities that were in the Introduction stage at time $\mathrm{T}_{0}, 10 \%$ progressed to the Growth stage, $70 \%$ to the Mature stage, and $10 \%$ to the Decline stage. The final $10 \%$ remained in the Introduction stage, and none were in the Shakeout stage, indicating a four-stage life cycle. The $\mathrm{T}_{0}-\mathrm{T}_{2}$ movements of these companies are shown in Figure 2.

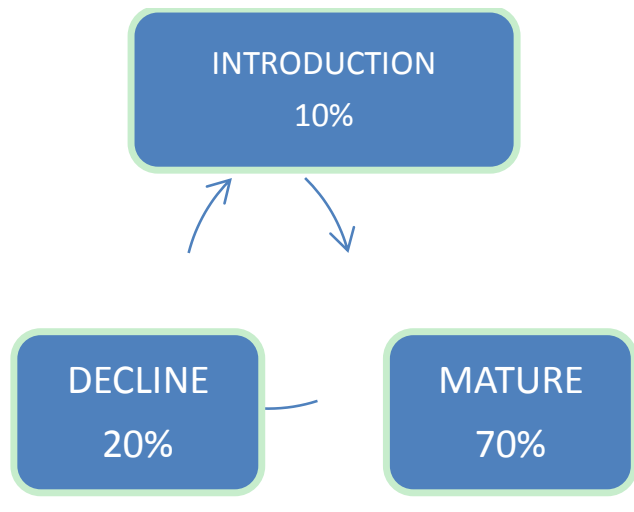

Figure 2. The life cycle stages at $\mathrm{T}_{2}$ of entities in the Introduction stage at $\mathrm{T}_{0}$ 
As shown in Figure 2, one year after $T_{1}$, no companies were in the Growth stage, and the percentage of companies in the Decline stage exhibited a corresponding increase. This finding indicates that companies can migrate to any stage at any time.

The pattern of these companies at $\mathrm{T}_{3}$ is shown in Figure 3.


Figure 3. The life cycle stages at $T_{3}$ of entities in the Introduction stage at $T_{0}$

At $\mathrm{T}_{3}$, companies moved back to the initial stage, i.e., the Introduction stage (20\%), with a corresponding decrease in the percentage in the Decline stage to $10 \%$. By contrast, the percentage of companies in the Mature stage remained constant from $\mathrm{T}_{1}$ through $\mathrm{T}_{3}$ at $70 \%$. Thus, throughout the study period, the companies gradually returned to their original state or developed into more mature companies.

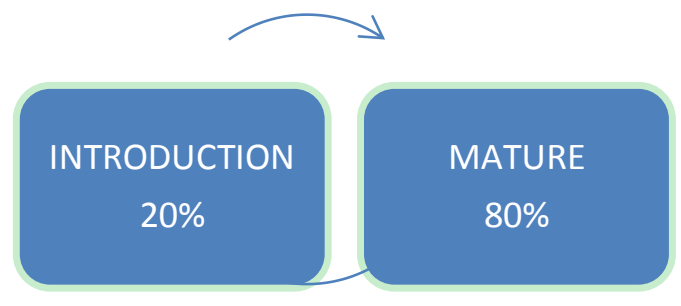

Figure 4. The life cycle stages at $\mathrm{T}_{4}$ of entities in the Introduction stage at $\mathrm{T}_{0}$

As shown in Figure 4, at $\mathrm{T}_{4}$, only two stages characterised the companies that were in the Introduction stage at $\mathrm{T}_{0}$. That is, 20 percent back to the introduction stage while 80 percent of the companies were at the matured stage.

Similar analyses were performed for companies in the Growth through Decline stages at $\mathrm{T}_{0}$ to elucidate the trends of development of these companies. The results are shown in Table 4. Growth firms developed most quickly into Shakeout firms ( $38 \%$ at $\mathrm{T}_{1}$ ), but at $\mathrm{T}_{2}$, Shakeout firms were absent, with corresponding increases in the Mature and Decline stages at a ratio of approximately 1:2 (i.e., from $25 \%$ to $38 \%$ and from 0 to $25 \%$, respectively). At $\mathrm{T}_{3}, 63 \%$ of the Growth firms at $\mathrm{T}_{0}$ had developed into the Mature stage, and only $13 \%$ remained in each of the Growth, Shakeout, and Decline stages. At $\mathrm{T}_{4}$, only 38\% of these firms were in the Mature stage, 25\% remained in the Growth stage, and none moved to the Decline stage. The percentage of Shakeout firms remained unchanged compared to $T_{3}$.

The Mature stage appeared to be the most stable firm stage. Firms in this stage at $\mathrm{T}_{0}$ largely remained so (ranging between $57 \%$ and $65 \%$ ). Mature firms were more likely to transit to the Growth stage than to the Shakeout stage at $\mathrm{T}_{1}$. 
Shakeout firms developed to the Mature stage rapidly (ranging from $42 \%$ to $58 \%$ ). By $\mathrm{T}_{3}$ and $\mathrm{T}_{4}, 17 \%$ of Shakeout firms had transited back to that stage. Among Decline firms, $60 \%$ remained in the Decline stage at $\mathrm{T}_{1}$, but this percentage decreased to $40 \%$ at $\mathrm{T}_{2}$. By $\mathrm{T}_{3}, 80 \%$ and $20 \%$ of the firms had transited to the Mature and Growth stages, respectively. However, in the year $\mathrm{T}_{4}$, these companies faded away, leaving $20 \%$ in each of the Introduction and Decline stages. Thus, in the fourth year, the probability of extinction of a Decline company was $60 \%$. These results indicate that the development of a firm's life cycle stage does not follow a regular sequence, supporting the null hypothesis.

\section{Conclusion}

This study aimed to ascertain whether organisational development is sequential, as reported by Walton (1980), Quinn and Cameron (1983), Miller and Friesen (1984), and Gibson et al. (1994), or random, as predicted by Tichy, (1980), Miller \& Friesen, (1984), Lester, et al., (2003) and Dickinson (2011). In this study, OLC theory was tested based on an analysis of the development patterns of organisations in Nigeria over a period of five years (2009 to 2013) using cash flow patterns as a classification proxy. The results indicate that the organisational life cycle develops in a random or stochastic manner and not sequentially, consistent with Dickinson (2011). The mature stage is the most stable, as they persistently remained in the stage and the shakeout stage the most unstable stage. However, if a shakeout firm can remain in that stage after two years, there is the probability that it could be stable at that stage for a while. On the other hands, the development of the organisation was also widely influenced by the level of the corporate taxation level in their operation activities (Rashid, Noor, Mastuki, \& Bardai, 2015). Firms in their introductory stage easily transit the mature stage or remain in the introductory stage. They seldom transit to shakeout and growth stages. Life cycle stages are not sequential, and the optimum stage is the matured stage. This is because companies in that stage remained stable most of the time. The researchers recommend that organisations should use their cash flow pattern to understand their life cycle stage and which will enable management to apply strategies to enhance their entity's life cycle stage. Also, researchers should use Cash Flow Patterns (CFP) to identify and make recommendations to address the category of firms studied. This will help to address the specific problems of the specific organisational stage. Future studies should include longitudinal analyses to reveal long-term trends and, potentially, new inferences.

\section{References}

Adizes, I. (1989). Corporate lifecycles: How and why corporations grow and die and what to do about it. Englewood Cliffs, New Jersey: Prentice-Hall.

Anthony, J. H., \& Ramesh, K. (1992). Association between accounting performance measures and stock prices: A test of the life cycle hypothesis. Journal of Accounting and Economics, 15(2-3), 203- 227.

Bess, J. (1984). College and University organisation. New York: New York University Press, p. 43

Black, E. L. (1998). Life-cycle impacts on the incremental value relevance of earnings and cash flow measures. Journal of Financial Statement Analysis, 4, 40-56.

Cruz, M. (2014). The secret to business immortality: The impact of the business life cycle. Retrieved 30 November 2017, from //books.google.com.ng>books

Dickinson, V. (2011). Cash flow patterns as a proxy for the firm life cycle. The Accounting Review, 86(6), 1969-1994.

Fischer, M. M. (2006). Innovation, networks, and knowledge spillovers: Selected essays. Germany: Springer Berlin.

Gaver, J. J., \& Gaver, K. M. (1993). Additional evidence on the association between the investment opportunity set and corporate financing, dividend and compensation policies. Journal of Accounting and Economics, 16, 125-162.

Gibson, J. L., Ivancevich, J. M., \& Donnelly, J. H. (1994). Organisations: Behavior, structure, processes. Richard D Irwin, Burr Ridge, IL.

Greiner, L. E. (1972). Evolution and revolution as organisations grow. Harvard Business Review, 50, 37-46.

Haire, M. (1959). Modern Organization Theory. John Wiley and Sons, New York, NY.

Hanks, S. H., Watson, C. J., Jensen, E., \& Chandler, G. N. (1993). Tightening the life cycle construct: A taxonomic study of growth stage configurations in high technology organisations. Entrepreneurship Theory and Practice, $18,5-30$.

Jaafar, H., \& Halim, H. A. (2015). Refining the firm life cycle classification methods: A firm value perspective. Journal of Economics, Business \& Management, 4(2), 112-119. 
Jenkins, D. S., Kane, G. D., \& Velury, U. (2004). The impact of the corporate life-cycle on the value-relevance of disaggregated earnings components. Review of Accounting \& Finance, 3, 5-20.

Kousenidis, D. V. (2005). Earnings-returns relation in Greece: Some evidence on the size effect and the life-cycle hypothesis. Managerial Finance, 31, 24-54.

Lester, D. L., Parnell, J. A., \& Carraher, S. (2003). Organizational life-cycle: A five stage empirical scale. International Journal of Organizational Analysis, 11, 339-354.

Martinez, I. (2003). The impact of firm-specific attributes on the relevance in earnings and cash-flows: A non-linear relationship between stock returns and accounting numbers. Review of Accounting \& Finance, 2, 16-40.

Miller, D., \& Friesen, P. H. (1980). Momentum and revolution in organisational adaptation. The Academy of Management Journal, 23(4), 591-614.

Miller, D., \& Friesen, P. H. (1984). A longitudinal study of the corporate life cycle. Management Science, 30(10), 1161-1183.

Mustapha, U. A., Rashid, N., Hussaini, B., \& Habibu, M. (2020, January). Corporate Governance and Financial Performance of Nigeria Listed Banks. Journal of Advanced Research in Dynamical \& Control Systems, 12(1). https://doi.org/10.5373/JARDCS/V12I1/20201002

Obasi, R., \& Ekwueme, M. (2016). Age and cash flow patterns as proxies for classifying firm's lifecycle stages in the Nigerian quoted companies. ICAN Journal of Accounting and Finance, 5(1), 64-79.

Park, Y., \& Chen, K. H. (2006). The effect of accounting conservatism and life-cycle stages on firm valuation. Journal of Applied Business Research, 22, 75-92.

Parker, P. P. (2018). The life cycle of a democratic society (and where are we in that cycle). Retrieved May 7, 2018, from https://wakeup.world.com

Quinn, R. E., \& Cameron, K. (1983). Organizational life cycles and shifting criteria of effectiveness: Some preliminary evidence. Management Science, 29(1), 33-51.

Rashid, N. M. N. N. M., Noor, R. M., Mastuki, N. A., \& Bardai, B. (2015, May). A longitudinal study of corporate tax planning: Analysis of companies' tax expense and financial ratios. Pertanika Journal of Social Science and Humanities, 23, 109-120.

Tichy, N. M. (1980). Organisation development and bureaucracy in the 1980s. The Journal of Applied Behavioral Science, 16(3), 423-437.

Walton, R. (1980). Establishing and maintaining high commitment work systems. In Kimberly, J. \& Miles, R. (Eds.), Organizational Life Cycle (pp. 208-290). Jossey Bass, San Francisco, CA.

Yan, Z., \& Zhao, Y. (2010). A new methodology of measuring firm life-cycle stages. International Journal of Economic Perspectives, 4, 579-587. 